\title{
GIS-based multi-criteria land suitability analysis for sustainable agriculture in the northeast area of Tadla plain (Morocco)
}

\author{
Widad Ennaji, Ahmed Barakat*, Mohamed El Baghdadi, Hakima Oumenskou, \\ Mohamed Aadraoui, Lalla Aicha Karroum and Abdessamad Hilali \\ GeoRessources and Environment Laboratory, Faculty of Sciences and Techniques, Sultan Moulay Slimane \\ University, Béni-Mellal, Morocco. \\ *Corresponding author. e-mail: a.barakat@usms.ma
}

MS received 3 July 2017; revised 7 January 2018; accepted 23 January 2018; published online 30 July 2018

Assessment of soil suitability for sustainable intensive agriculture is an appropriate tool to select the land suitable for agricultural production with the least economic and environmental costs. This study was conducted to evaluate the agricultural soil quality in the northeast area of Tadla plain (Morocco) using geographic information system (GIS) and analytical hierarchy process (AHP). Six soil quality indicators, i.e., pH, organic carbon, cation exchange capacity, texture, salinity and slope were considered and performed in 60 subsurface soil samples. AHP method was utilized to identify the weight of each indicator from the pairwise comparison matrix. The weighted sum overlay analysis was then used to generate the soil quality map in a GIS environment, by overlaying both indicator weights and subindicator weights. The studied area was classified into four soil quality categories, i.e., poor, medium, good, and excellent, the percentage of each category is $1.12,20.98,61.07$ and $16.83 \%$, respectively. The results indicated that $1.12 \%$ of the study area has poor suitability for sustainable intensive agriculture due to their unsuitable texture and low salinity, while about $77 \%$ of cultivated soils are adapted to agricultural production. The above results could be useful for the management of agricultural activity.

Keywords. Tadla plain; soil quality; AHP method; GIS; indicator; intensive agriculture.

\section{Introduction}

Agricultural soils are more important for supporting crop production and for maintaining clean water and air, reducing greenhouse gas emissions, preserving natural biodiversity and ensuring food quality (Bremer and Ellert 2004). With the growing demand for crop production in relation to increase in global population, assessing soil quality has become a serious challenge to understand the dynamics and distribution of the soil characteristics that are critical for predicting future sustainable use of each soil quality. Nevertheless, the concept of the soil quality is not well defined, because it belongs strongly to the outlook of the land users. As a result, many indicators were recently taken on soil quality evaluation based upon uses and contexts of lands since soil properties vary greatly across soil types and management systems (Herrick et al. 2002; Bremer and Ellert 2004; Aparicio and Costa 2007; Bastida et al. 2008; Filep et al. 2016; Barakat et al. 2017a). The 
combination and comparison of such indicators and their spatial analysis and modeling were made possible with advancements of geographical information systems (GIS) that are capable of handling different types of data (Kumar and Hassan 2013). More benefits of using GIS in soil quality assessment have been demonstrated in many research studies (i.e., Akıncs et al. 2013; Feizizadeh and Blaschke 2013; Nguyen et al. 2015; Kazemi et al. 2016; Barakat et al. 2017a; Mokarram and Hojati 2017). Most of these studies used multicriteria evaluation (MCE) with GIS. The use of GIS multicriteria decision making (MCDM) methods allowed having information from different data, necessary to identify the most appropriate spatial pattern for future soil uses. Developed in 1960 to assist with decision-making, MCE is a device which enables the most appropriate choice to be made among many criteria (Cay and Uyan 2013). The analytical hierarchy process (AHP) becomes a multi-attribute technique that has been applied to the land evaluation techniques, and also allows the weights of these multiple and heterogeneous criteria to be determined according to relative importance (i.e., Zhang et al. 2015; Zolekar and Bhagat 2015; Nie et al. 2016; Wali et al. 2016; Yalew et al. 2016; Barakat et al. 2017b). Therefore, MCE based AHP and GIS techniques were used in our study to help interpret the data from different soil measurements and to map the soil suitability for sustainable agriculture in the northeast area of Tadla plain using the influencing indicators.

Morocco operates $\sim 9.2$ million hectares for agriculture, which constitute the most important economic sector. In addition, agriculture is regarded as very vulnerable to climate change and also to the agricultural pollution. However, over the time, intensive farming and inadequate human activity has contributed to land degradation in many irrigated agricultural areas such as the

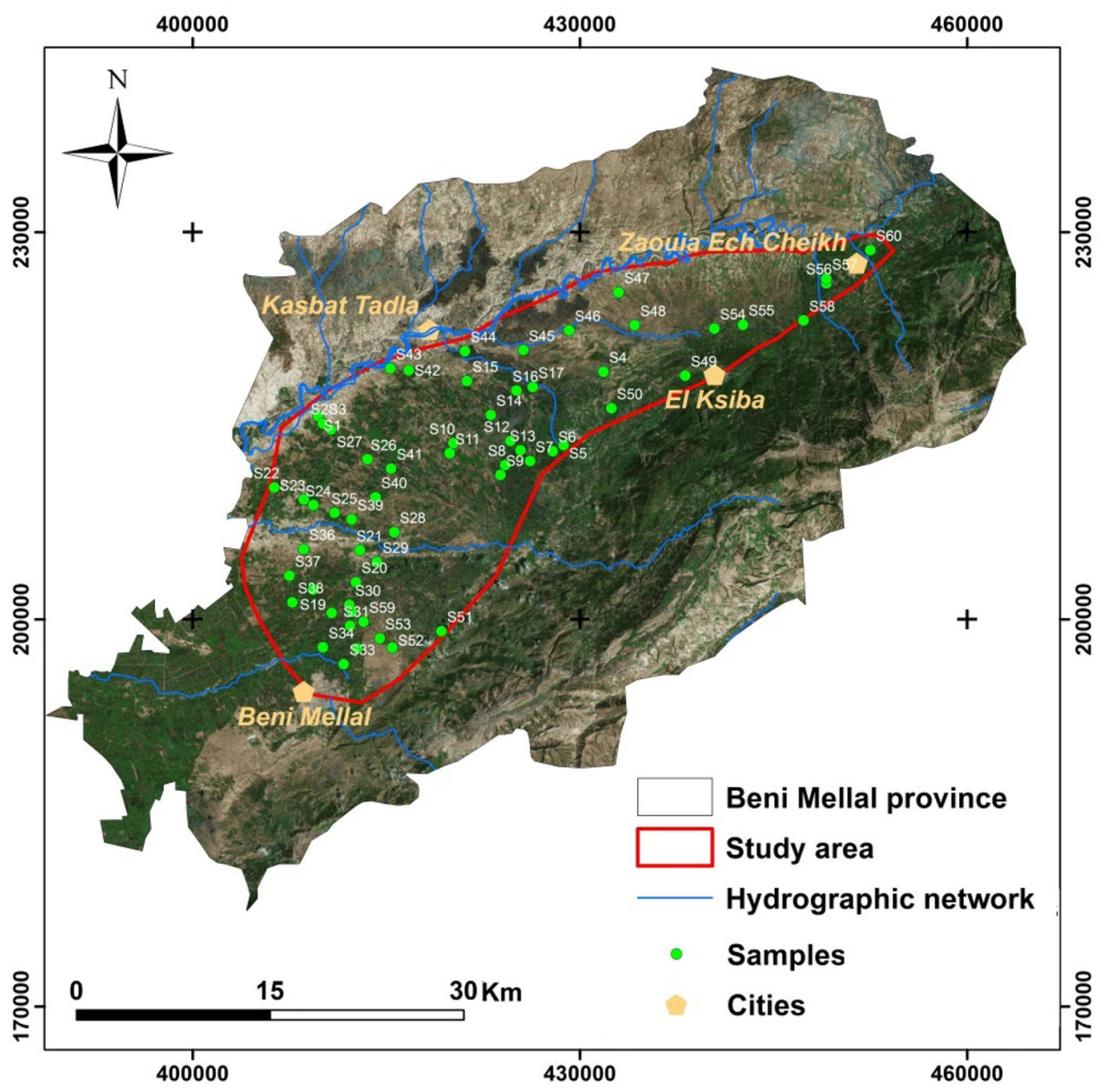

Figure 1. Location map of the study area. (a) National scale and (b) regional scale. 
Table 1. The soil quality parameters and their analytical method in this study.

\begin{tabular}{lll}
\hline Parameter & \multicolumn{1}{c}{ Analytical method } & Unit \\
\hline $\mathrm{pH}$ & Method of McLean (1982) & in $\mathrm{H}_{2} \mathrm{O}$ \\
Soil texture & Robinson's pipette method & $\%$ \\
Organic carbon & Spectrometry after oxidation in a sulfochromic & $\%$ \\
Salinity & Saturation extracts(Richards) & $\mathrm{dS} / \mathrm{m}$ \\
Cation-exchange capacity & Metson method (1956) & $\mathrm{Cmol} / \mathrm{kg}$ \\
Slope & The digital terrain model & $\%$ \\
\hline
\end{tabular}

Table 2. Analysis result of soil quality indicators and statistical summary.

\begin{tabular}{|c|c|c|c|c|c|}
\hline $\begin{array}{l}\text { Indicators } \\
\text { Samples }\end{array}$ & $\begin{array}{c}\mathrm{pH} \\
\left(\mathrm{H}_{2} \mathrm{O}\right)\end{array}$ & $\begin{array}{c}\mathrm{CEC} \\
(\mathrm{Cmol} / \mathrm{kg})\end{array}$ & $\begin{array}{l}\mathrm{OC} \\
(\%)\end{array}$ & $\begin{array}{c}\text { Clay and silt } \\
(\%)\end{array}$ & $\begin{array}{l}\text { Salinity } \\
(\mathrm{dS} / \mathrm{m})\end{array}$ \\
\hline $\mathrm{S} 1$ & 8.5 & 21.5 & 1.05 & 68 & 1.82 \\
\hline $\mathrm{S} 2$ & 8.6 & 29.2 & 1.59 & 74 & 1.462 \\
\hline S3 & 8.4 & 16.5 & 1.43 & 55.3 & 1.14 \\
\hline $\mathrm{S} 4$ & 8.1 & 10.7 & 1.30 & 27.7 & 0.98 \\
\hline $\mathrm{S} 5$ & 8.2 & 30.8 & 1.68 & 76.7 & 0.946 \\
\hline S6 & 8.3 & 29.6 & 1.60 & 78.3 & 1.032 \\
\hline $\mathrm{S} 7$ & 8.1 & 35.5 & 1.80 & 75.7 & 1.634 \\
\hline S8 & 8.3 & 44.2 & 1.43 & 75.7 & 1.032 \\
\hline S9 & 8.3 & 37.7 & 1.58 & 69.8 & 1.032 \\
\hline $\mathrm{S} 10$ & 8.5 & 23.4 & 1.61 & 51.5 & 1.29 \\
\hline $\mathrm{S} 11$ & 8.3 & 23.5 & 1.77 & 56.5 & 2.38 \\
\hline S12 & 8.1 & 34.6 & 1.28 & 69.8 & 0.688 \\
\hline $\mathrm{S} 13$ & 8.2 & 37.4 & 1.66 & 80 & 0.946 \\
\hline S14 & 8.5 & 21.1 & 0.71 & 61.1 & 1.68 \\
\hline S15 & 8.3 & 21.5 & 2.20 & 68.4 & 1.29 \\
\hline $\mathrm{S} 16$ & 8.3 & 39.7 & 1.66 & 79 & 1.29 \\
\hline $\mathrm{S} 17$ & 8.1 & 43.9 & 1.95 & 76.2 & 1.118 \\
\hline $\mathrm{S} 18$ & 8.1 & 33.4 & 1.18 & 75.5 & 0.516 \\
\hline S19 & 8 & 30.7 & 1.26 & 74.5 & 0.774 \\
\hline S20 & 8.4 & 29.9 & 1.24 & 81.5 & 1.032 \\
\hline $\mathrm{S} 21$ & 8.3 & 18.3 & 1.43 & 61.5 & 1.96 \\
\hline $\mathrm{S} 22$ & 8.2 & 27.6 & 2.06 & 71.5 & 2.322 \\
\hline $\mathrm{S} 23$ & 8.5 & 25.8 & 1.62 & 65.5 & 1.96 \\
\hline S24 & 8.3 & 18.1 & 1.43 & 66.5 & 2.94 \\
\hline $\mathrm{S} 25$ & 8.5 & 29 & 1.66 & 70.1 & 1.29 \\
\hline $\mathrm{S} 26$ & 8.5 & 30.3 & 1.62 & 70 & 1.118 \\
\hline $\mathrm{S} 27$ & 8.3 & 33.8 & 2.25 & 72 & 1.548 \\
\hline S28 & 8.5 & 27.5 & 1.49 & 61.9 & 1.96 \\
\hline S29 & 8 & 32.6 & 1.47 & 64.7 & 1.892 \\
\hline S30 & 8.3 & 26.6 & 2.07 & 59.7 & 1.29 \\
\hline S31 & 8.4 & 14.2 & 0.94 & 52 & 1.33 \\
\hline S32 & 8.3 & 22.4 & 2.19 & 56.5 & 1.82 \\
\hline S33 & 8.3 & 18.7 & 1.55 & 62.5 & 2.52 \\
\hline S34 & 8.5 & 28.4 & 1.40 & 68.5 & 1.118 \\
\hline S35 & 8.2 & 29.6 & 2.05 & 60.1 & 1.806 \\
\hline S36 & 8.4 & 19.7 & 1.79 & 67.7 & 2.8 \\
\hline S37 & 8.4 & 25.3 & 1.32 & 59.3 & 1.54 \\
\hline S38 & 8.5 & 19.2 & 1.16 & 63 & 2.38 \\
\hline S39 & 8.5 & 12.6 & 0.70 & 26.8 & 2.1 \\
\hline $\mathrm{S} 40$ & 8.2 & 34.5 & 1.44 & 66.7 & 0.946 \\
\hline $\mathrm{S} 41$ & 8.3 & 35.9 & 1.41 & 64.8 & 1.204 \\
\hline $\mathrm{S} 42$ & 8.6 & 23.1 & 0.96 & 49.6 & 1.14 \\
\hline
\end{tabular}


Table 2. (Continued.)

\begin{tabular}{llllll}
\hline $\begin{array}{l}\text { Indicators } \\
\text { Samples }\end{array}$ & $\begin{array}{c}\mathrm{pH} \\
\left(\mathrm{H}_{2} \mathrm{O}\right)\end{array}$ & $\begin{array}{c}\mathrm{CEC} \\
(\mathrm{Cmol} / \mathrm{kg})\end{array}$ & $\begin{array}{c}\text { OC } \\
(\%)\end{array}$ & $\begin{array}{c}\text { Clay and silt } \\
(\%)\end{array}$ & $\begin{array}{c}\text { Salinity } \\
(\mathrm{dS} / \mathrm{m})\end{array}$ \\
\hline $\mathrm{S} 43$ & 8.3 & 20.2 & 1.69 & 53.7 & 2.52 \\
$\mathrm{~S} 44$ & 8.4 & 48.6 & 1.18 & 84.5 & 2.15 \\
$\mathrm{~S} 45$ & 8.1 & 25.3 & 1.28 & 53.5 & 1.032 \\
$\mathrm{~S} 46$ & 8.3 & 23.9 & 2.12 & 64.7 & 2.1 \\
$\mathrm{~S} 47$ & 8.3 & 40.8 & 2.96 & 75.3 & 1.376 \\
S48 & 8 & 26.4 & 2.24 & 59.9 & 0.86 \\
S49 & 7.6 & 19.1 & 1.82 & 68.5 & 1.12 \\
S50 & 8.3 & 32.9 & 2.52 & 84 & 2.236 \\
S51 & 8.3 & 26.4 & 2.72 & 65.5 & 2.1 \\
S52 & 7.9 & 24.7 & 1.94 & 68.5 & 1.032 \\
S53 & 8.3 & 23.8 & 1.87 & 58.8 & 1.68 \\
S54 & 8 & 23 & 2.04 & 69.3 & 1.032 \\
S55 & 8.3 & 30.5 & 2.21 & 75.2 & 1.118 \\
S56 & 19.3 & 1.69 & 71 & 1.68 \\
S57 & 8.4 & 22.1 & 2.26 & 65.2 & 2.66 \\
S58 & 8.3 & 35.6 & 2.43 & 86.3 & 1.118 \\
S59 & 8.2 & 23.3 & 1.42 & 61.2 & 1.032 \\
S60 & 8.5 & 32.2 & 1.58 & 76.8 & 1.29 \\
Min & 8.3 & 10.7 & 0.70 & 26.8 & 0.516 \\
Max & 7.6 & 48.6 & 2.96 & 86.3 & 2.94 \\
Mean & 8.6 & 7.932 & 0.46 & 11.310 & 1.52 \\
Standard deviation & 0.184 & & & 0.578
\end{tabular}

irrigated Tadla plain, perimeter of Souss-Massa and irrigated perimeter of Haouz (Debbarh and Badraoui 2001). Over-fertilization, excessive irrigation and destruction of vegetation roots are often responsible for runoff, soil loss, discharge of pollutants and sediments to surface and groundwater bodies, nutrient deficiency, salinization and water logging of soil (Barakat et al. 2016b, 2017a; Harti 2016). These effects could undoubtedly reduce the fertility and ability of the soil to sustain crop growth, which could affect consequently agricultural production. To conserve the soil functions, it is necessary to mitigate the negative impact of the agricultural intensification on the quality of soil, water, air, and biodiversity. Sustainable intensive agriculture is a recent approach aimed to increase food production on the planet for adequately feeding the world's population, while preserving the ecosystem processes and the world's natural resources. With inadequate agricultural intensification added to the fragile ecosystem characterized by the arid climate, Morocco is beginning to have a serious problem not only on soil fertility, but also on quantity and quality of freshwater, and biodiversity. The soil nutrients became insufficient to meet the higher nutrient demands of intensive agriculture, and the chemical fertilizer inputs would contribute to soil acidification and salinization that will decline the soil fertility. Under these circumstances, practices of sustainable agriculture based on knowledge of the soil functions are required for most agricultural regions of the country.

The present study was conducted with the objective to evaluate the quality of soil in the northeast part of the Tadla plain (Morocco) to support a sustainable agriculture without ecosystem deterioration and with minimum low economic and environmental costs, using GIS and AHP techniques. In this study, in addition to the topographic indicator (slope), the subsurface soil samples were monitored to characterize contents of five soil quality indicators suggested in the previous literature for lands, such as $\mathrm{pH}$, organic carbon, cation exchange capacity (CEC), texture and salinity that is often reported as a lumped parameter, i.e., electrical conductivity (EC). Integration of GIS and AHP methods has been approached to determine the distribution and areas of land suitable for intense agriculture in the context of sustainable development. The results of this study would be crucial for making decisions on sustainable land management in the northeast area of Tadla plain. 


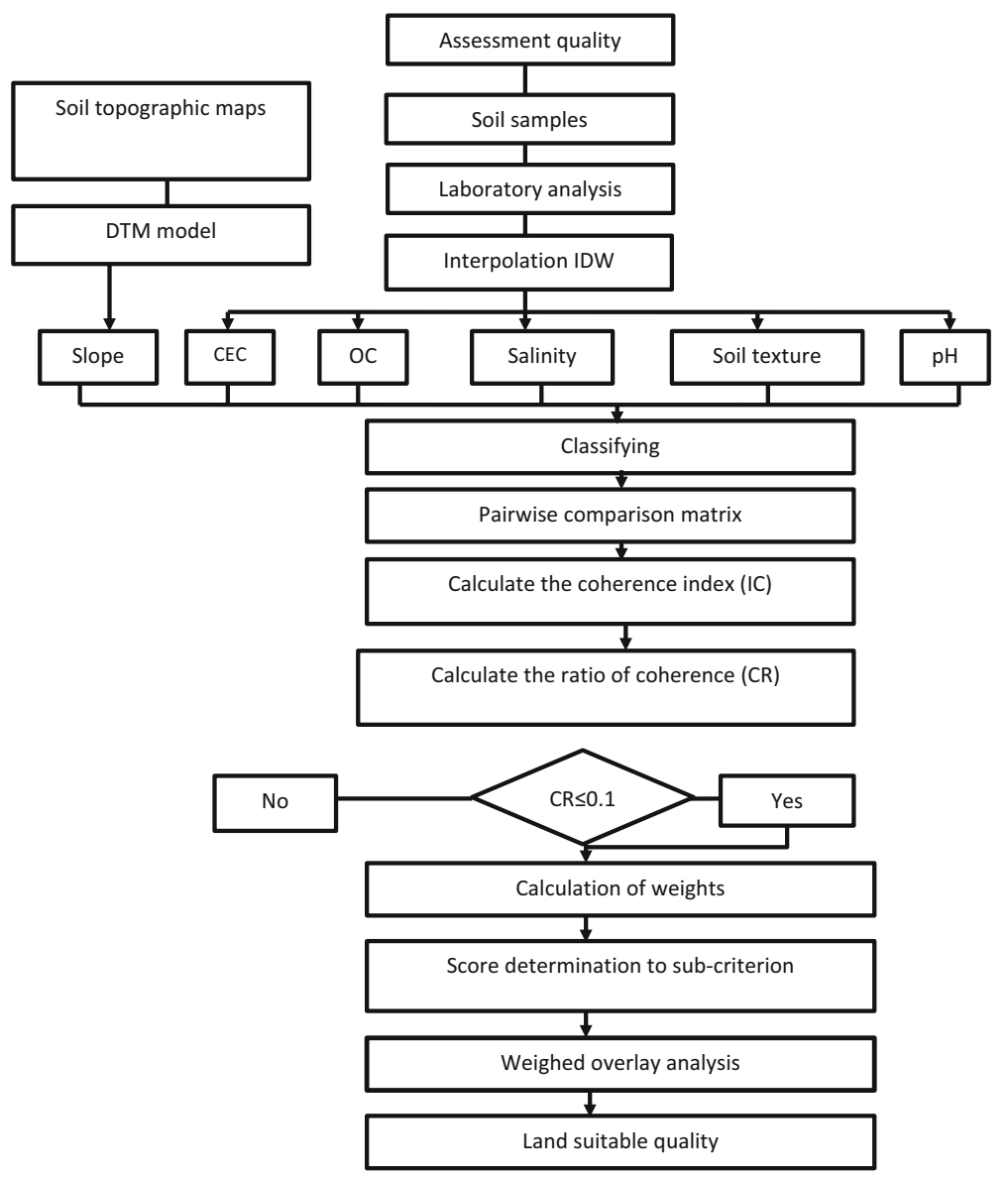

Figure 2. Procedure followed in applying the AHP method.

Table 3. Saaty and Vargas preference scales.

\begin{tabular}{lc}
\hline Description & $\begin{array}{c}\text { Intensity of } \\
\text { importance }\end{array}$ \\
\hline Equal importance & 1 \\
Equal to average importance & 2 \\
Average importance & 3 \\
Average to strong importance & 4 \\
Strong importance & 5 \\
Strong to very strong importance & 6 \\
Very strong importance & 7 \\
Very strong or superstrong importance & 8 \\
Superstrong importance & 9 \\
\hline
\end{tabular}

\section{Material and methods}

The methodology used in this study is aimed to generate the suitability map of the quality of the agricultural soils in the study area. Two important steps applied in this process or system consist of two parts. The first is devoted to data preparation and the second is intended to land suitability assessment as illustrated in figures 2 and 3. The objectives are to (i) characterize the physicochemical properties of the soil by laboratory analysis and generate interpolation maps of each parameter using inverse distance weighted (IDW), and (ii) elaborate the soil quality map in the study area using multi-criteria analytic hierarchy process (AHP) methods to identify suitable areas for agriculture.

\subsection{Study area}

The study area $\left(1100 \mathrm{~km}^{2}\right)$ corresponds to the northeast part of Tadla plain in Morocco center (figure 1). The Tadla plain is demarcated to the northeast by the phosphates' plateau, to the southeast by the Atlas Mountain of Béni-Mellal. The geological formations are mainly composed of limestone, marls, and sandstones. They range in age from Paleozoic to Quaternary (Bouchaou 2009). Altitude varies from 400 to $700 \mathrm{~m}$ with high peaks located close to the Atlas Piedmont. The annual 
Table 4. Detailed weights of indicators and sub-indicators obtained from AHP.

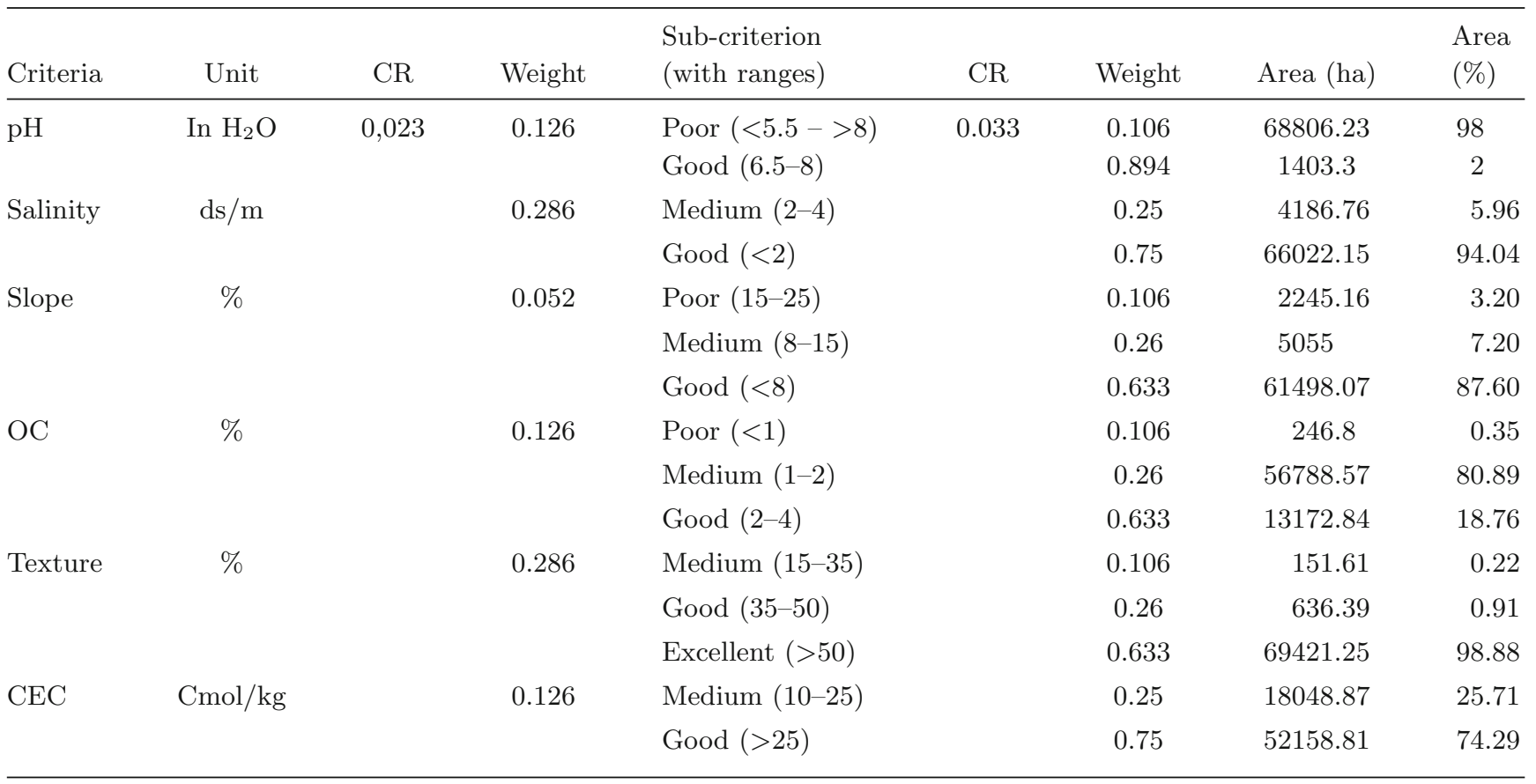

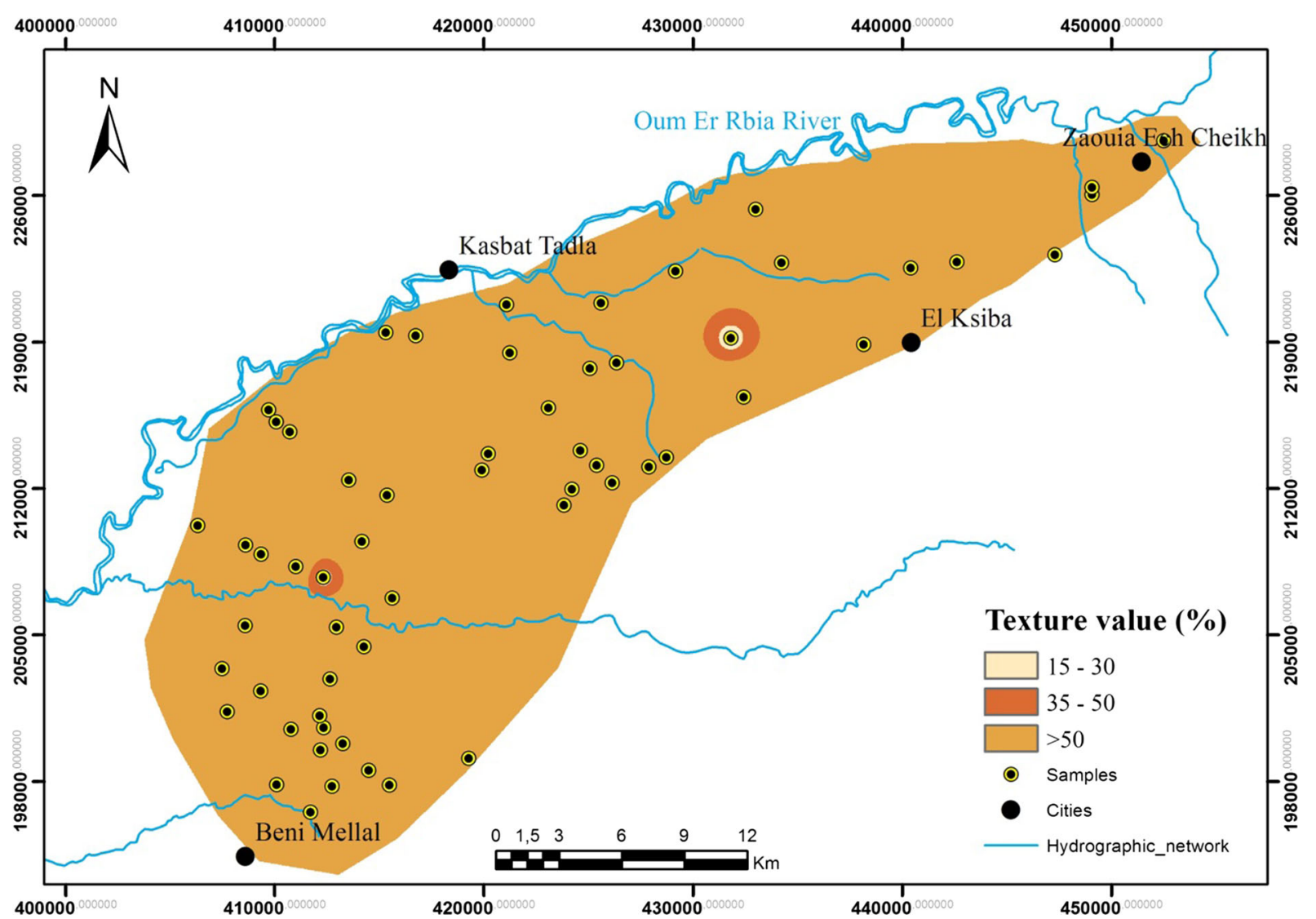

Figure 3. Spatial distribution of texture in the study area. 
temperatures range from $38^{\circ}$ to $40^{\circ} \mathrm{C}$ in summer and $3^{\circ}-4^{\circ} \mathrm{C}$ in winter. The average rainfall is $259 \mathrm{~mm} / \mathrm{yr}$ in the plain, while $456 \mathrm{~mm} / \mathrm{yr}$ in the mountain.

The Tadla plain contains some of the most important population in the Béni-Mellal_Khénifra region and includes its major economic and social centers such as Béni-Mellal and Fkih Ben Salah towns. Agriculture and livestock are the main sources of income to $62 \%$ of the region's active population. The farming systems are widely based on tillage sector that are largely characterized by cropping of cereals, pulse crops, sugar beets, forage and market gardening, olive and citrus fruits. Agriculture is dependent on soil quality and surface and groundwater resources of the region. The studied area is characterized by various subsoil resources and topography that makes it suitable for a variety of different purposes. The deep soils are used for arable farming due to its fertility and are distributed on foothill zones. The very shallow soil with rocky patches or parent rock are visible on steep slopes distributed on Atlas Piedmont that constitutes an important source for aggregate stone production (Barakat et al. 2016a, 2017a). These relationships between soil type and land use could affect the soil functions through alteration of their soil properties related to inappropriate farm actions such as excess in fertilization, irrigation and plowing (Barakat et al. 2017a). There, it is of crucial importance to assess the capacity of soil types to support intensive farming.

\subsection{Soil sampling and indicators analyzed}

In this study, 60 samples were collected from the agricultural soil of the northeast area of Tadla plain during March and April 2015, according to the sampling procedures. The soil samples were composite samples from the top $20 \mathrm{~cm}$ of four sampling points. The coordinates of each sample are recorded with the help of global positioning system (GPS) instrument. All soil samples were air-dried and sieved through a sieve of $2 \mathrm{~mm}$ stainless steel mesh, and then analyzed in GeoRessources and Environment Laboratory at the Faculty of Sciences and Techniques of Béni-Mellal, to detect physical and chemical parameters (indicators). For

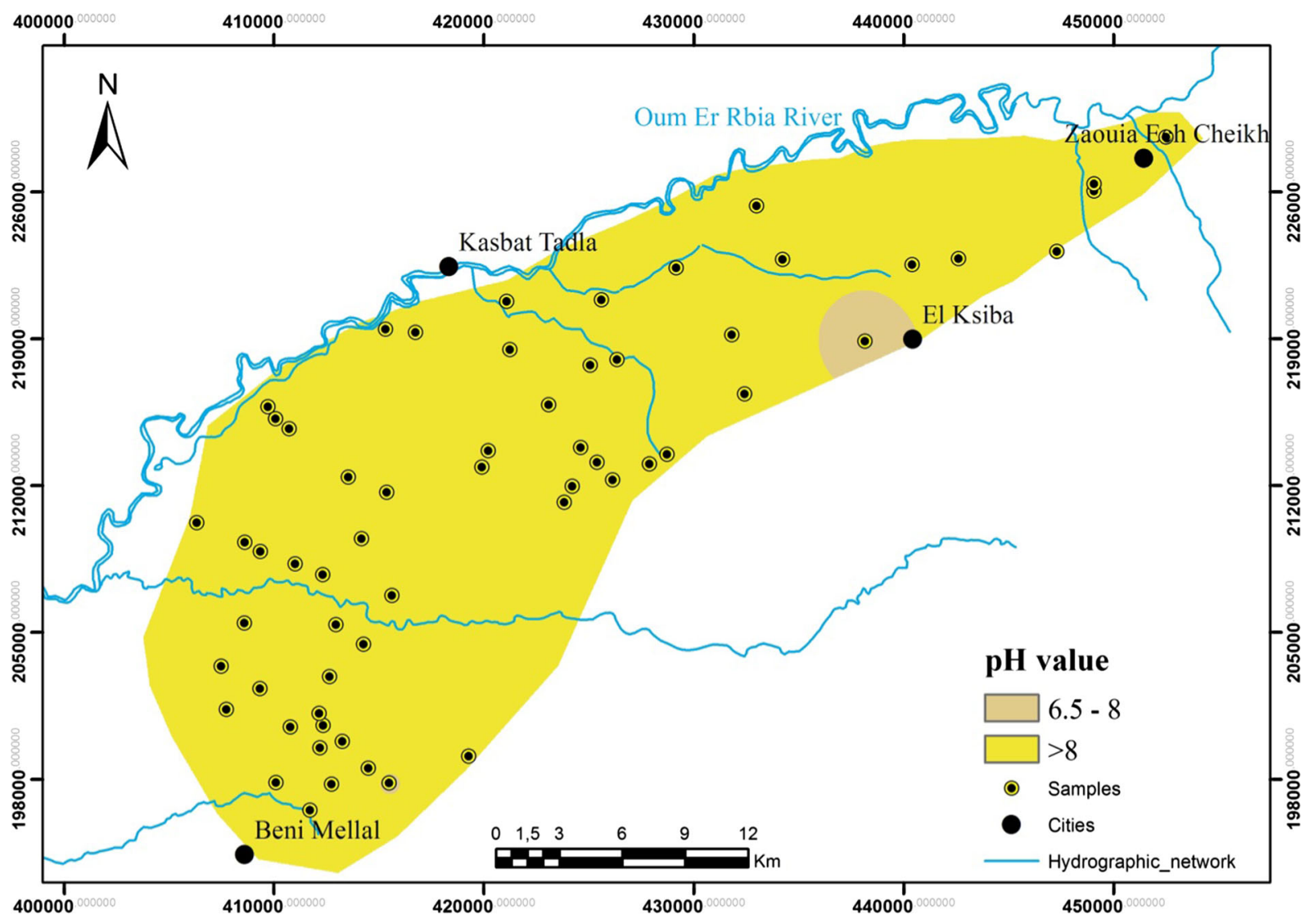

Figure 4. Spatial distribution of $\mathrm{pH}$ in the study area. 
accurate assessment of spatial soil fertility, some soil quality indicators that are frequently used for assessment of land quality and suitability for agriculture (Schiefer et al. 2015; Filep et al. 2016; Barakat et al. 2017a), i.e., slope, texture, pH, electrical conductivity (EC), cation exchange capacity (CEC), and organic carbon (OC) were used to map the land fertility in this study area. The monitored parameters, their units, statistical value and the methods of analysis are summarized in tables 1 and 2. The parameters used and the reasons for their selection are explained in detail in the following sections. Thematic maps of all analyzed parameters were prepared based on the obtained results, using inverse distance weighting (IWD) interpolation techniques. Slope map was prepared using digital elevation model $($ DEM) with a $30 \times 30 \mathrm{~m}$ cell size of the study area. All thematic maps were generated using ArcGIS software.

\subsection{AHP approach}

The AHP approach developed by Saaty (1977, 1990), is the most used multi-criteria method for quantifying the comparison of decision criteria in a pairwise technique (Laskar 2003). The steps involved in the AHP process used in this study can be outlined as: pairwise comparison, calculation of weights, and weighted overlay analysis (figure 2). The pairwise comparison is made using a scale with values from 1 to 9 (Saaty and Vargas 2001) (table 3) to evaluate the rank of the relative priorities of two criteria. The ranks of influencing criteria are created according to the experts' suggestions. To ensure the credibility of the relative influence ranking used, the consistency ratio index $(C R)$ will be calculated using equation (1)

$$
C R=\frac{C I}{R I}
$$

where $C I$ is the consistency index and $R I$ is the random matrix. Saaty (1977) suggests acceptable $C R$ values up to 0.1 , or a revised judgment for $C R$ exceeding 0.1 . The scores of sub-indicators (indicator buffers) were assigned, based on the literature (Barakat et al. 2017a), from 1 to 9 based on favourable conditions for sustainable agriculture,

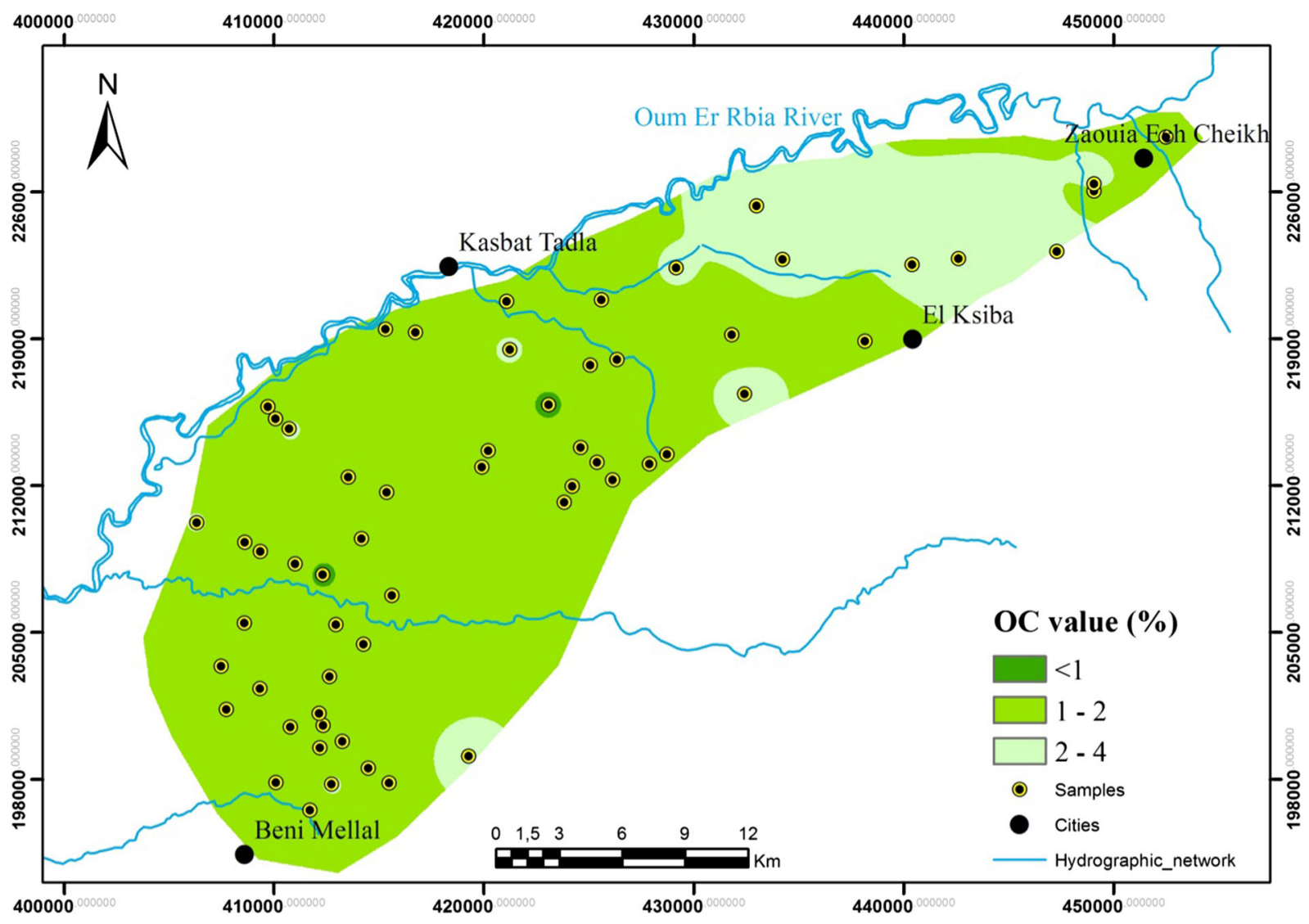

Figure 5. Spatial distribution of organic carbon in the study area. 
i.e., the higher score suggests maximum portance level of sub-indicators (table 4).

Then, all thematic layers were integrated with each other in GIS using the weighted overlay technique to produce the final land fertility map. The final map was determined by computing the land suitability index $(L S I)$, in the following manner

$L S I=\sum_{i=1}^{n} w_{i} * x_{i} \quad$ (after Cengiz and Akbulak 2009)

where $n$ is the total number of LS criteria, $w_{i}$ is the weight index of factor, and $x_{i}$ is the weight index of sub-criteria. Higher $L S I$ values indicate areas more suitable for sustainable agriculture.

The final suitability map generated using ArcGIS by combining six criteria maps and overlaying weighs of individual criteria, was reclassified into excellent suitable, good suitable, medium suitable, and poor suitable. The pairwise comparison matrix was created to determine the weights of parameters according to the AHP method (table 4). The experts' opinions were used to decide the ranks of influencing criteria and pairwise comparison matrix (PCM) in comparison to super decision software (CSDS) used to determine the weights.

\section{Results and discussion}

\subsection{Description of the soil indicators}

Delimitation of fertile areas is a very important process for a successful operation of the development of a sustainable intensive agriculture. Soil quality assessment involves an extensive evaluation process in order to identify the suitable good agricultural land location. The identified suitable soils must contain the major nutrients for basic plant nutrition in order to reduce organic, mineral chemical inputs to minimize economic cost and environmental damage. In this study, six soil quality indicators, namely slope, texture, $\mathrm{pH}, \mathrm{EC}, \mathrm{CEC}$, and $\mathrm{OC}$, were considered to map the soil quality for intensive agriculture in the northeast area of Tadla plain. All indicators are explained below, and their measured concentrations were summarized in table 2 .

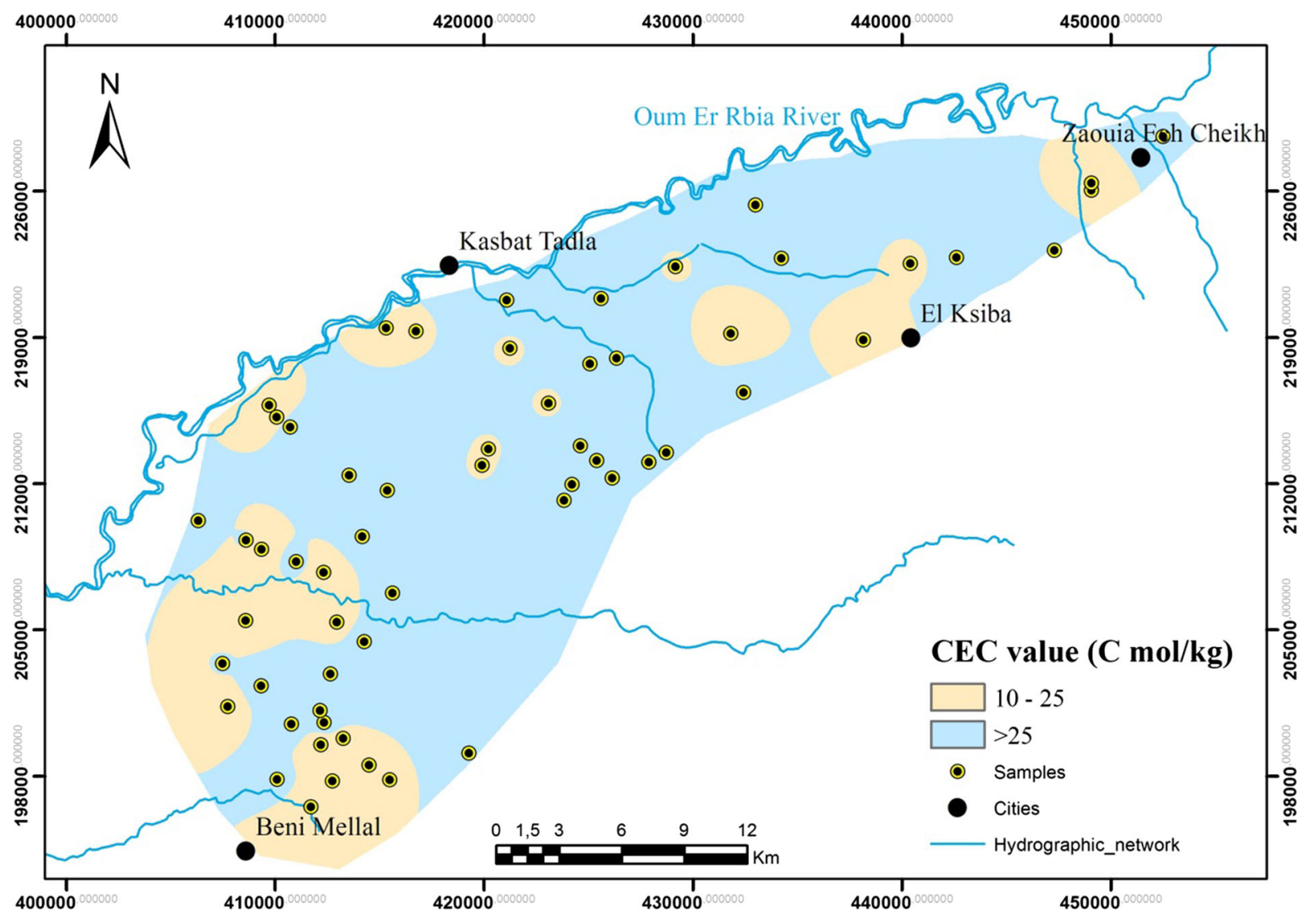

Figure 6. Spatial distribution of cation exchange capacity in the study area. 
Soil particle size is an important physical characteristic influencing the behaviour of plant growth as it impacts the soil texture, soil quality and soil erosion (Aderonke and Gbadegesin 2013). The contents of the clay and silt fraction measured in the studied soils ranged from 26.8 to $86.3 \%$. According to quality norms (table 4 ), the clay and silt fraction range is classified in medium, good and excellent quality categories covering $0.22 \%$ (151.61 ha), $0.91 \%$ (636.39 ha), 98.88\% (69421.25 ha) of the study area, respectively (figure 3 ).

Soil $\mathrm{pH}$ or soil reaction is a measure of the acidity or alkalinity in the soil and is measured in $\mathrm{pH}$ units. It is an important indicator of soil health because of its influence on the supply of nutrients (cations and anions) to plants and on the microbial activity. The soil $\mathrm{pH}$ value measured in water was ranging between 7.6 and 8.6 and classified into two categories: the poor quality level with a percentage of $98 \%$ (68806.23 ha) and in good quality level occupying about $1.10 \%$ (1403.3 ha) of the study area (figure 4).

The OC has long been identified as one of the important factors to soil fertility (Kucharik et al. 2001), because it serves as a source of plant nutrients, and aids in the soil pH buffering capacity. Moreover, organic carbon influences water relations, aeration, and workability through its influence on some soil's physical and chemical proprieties such as colour, soil structure, exchange capacity, nutrient turnover, nutrient-holding capacity, and stability. The OC values obtained ranged between 0.70 and $2.96 \%$ and showed thus that $0.35 \%$ (246.8 ha) of the total area had poor soil quality for intensive agriculture, $80.88 \%$ (56788.57 ha) was medium suitable, and $18.76 \%$ (13172.84 ha) was good suitable (figure 5).

CEC is a measure of the soil ability to hold positively charged ions. It is a very important soil property influencing soil structure stability, nutrient availability, soil $\mathrm{pH}$ and the soil reaction to fertilizers and other soil improvers. The CEC value in the study area ranged between 10.7 and 48.6 $\mathrm{Cmol} / \mathrm{kg}$ and classified into medium and good categories representing, respectively, about $25.71 \%$ (18048.87 ha) and $74,30 \%(52158,81$ ha) of the study area (figure 6).

Soil salinity refers to surface or near-surface accumulation of salts (Tanji 2002). The soils may become saline as a result of land use, including

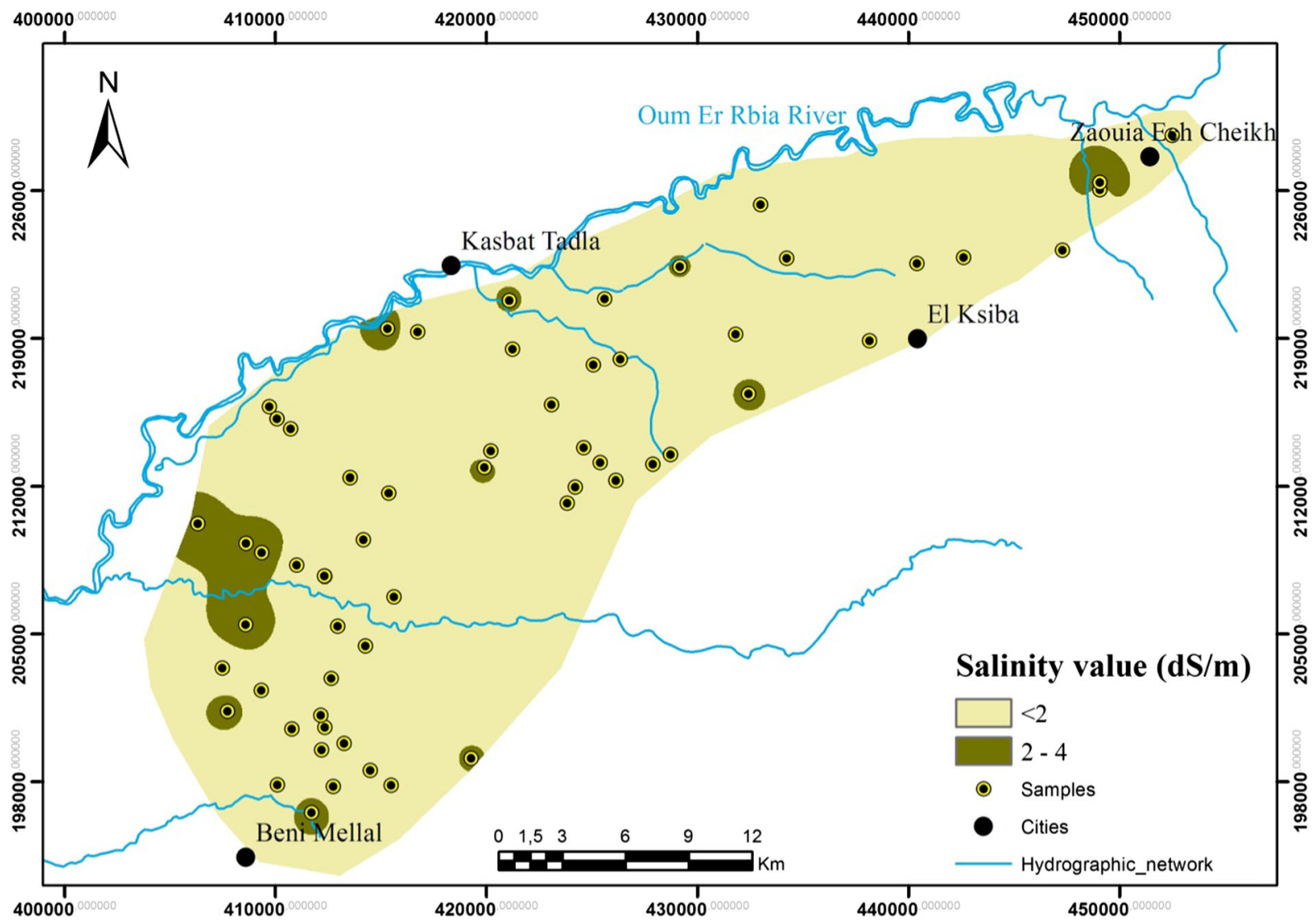

Figure 7. Spatial distribution of salinity in the study area. 
the use of irrigation water with high levels of salt. The measured salinity value ranged between 0.516 and $2.94 \mathrm{dS} / \mathrm{m}$, indicating thus a medium to good suitable soil quality for intensive agriculture. About $94.04 \%$ (66022.15 ha) of the study area is well suitable for agriculture, and only $5.97 \%$ (4186.76 ha) area shows medium suitability (figure 7).

Soil slope is particularly important in terms of its effect on erosion. The soil depth decreases with increasing slope rate and increases as the slope decreased (Atalay 2006). In the study area, the soil slope extracted from the DEM showed that $87.60 \%$ (61498.07 ha) of the total land is a flat area that is considered better for intensive agriculture; had good quality, $7.20 \%$ (5055 ha) has medium slope rate, and only $3.19 \%$ (2245.16 ha) is steep and consequently not suitable for intensive agriculture (figure 8).

\subsection{Land suitability map}

The use of GIS allows us to obtain thematic raster maps of independent physico-chemical variables corresponding to the soil quality indicators. According to the importance of these indicators, the weight of each indicator was calculated using AHP multi-criteria analysis (table 4), and then the soil quality map of the study area was generated by the superimposition of all thematic raster maps using the overlay weights sum extension in ArcGIS software's (figure 9). The land suitability map for sustainable intensive agriculture in the study area was generated and classified into four categories (figure 9), i.e., excellent, good, medium and poor soil quality. It showed that about 11807.51 ha of the investigated area is excellent suitable, 42849.74 ha are good suitable, 14714.61 ha had medium suitability, and only 787.56 ha had a poor quality of sustainable intensive agriculture. Together, the excellent and good suitability categories make up about $78 \%$ of the total area that could be recommended for intensive agriculture. Furthermore, $22 \%$ of the agricultural soil was delineated as not recommendable for agriculture (table 5). Geographically, these not recommendable areas are characterized by unsuitable texture and low salinity. These two factors were considered as limiting factors to categorize the soil quality of the study area located in the Tadla plain irrigated area, which encountered several problems such as

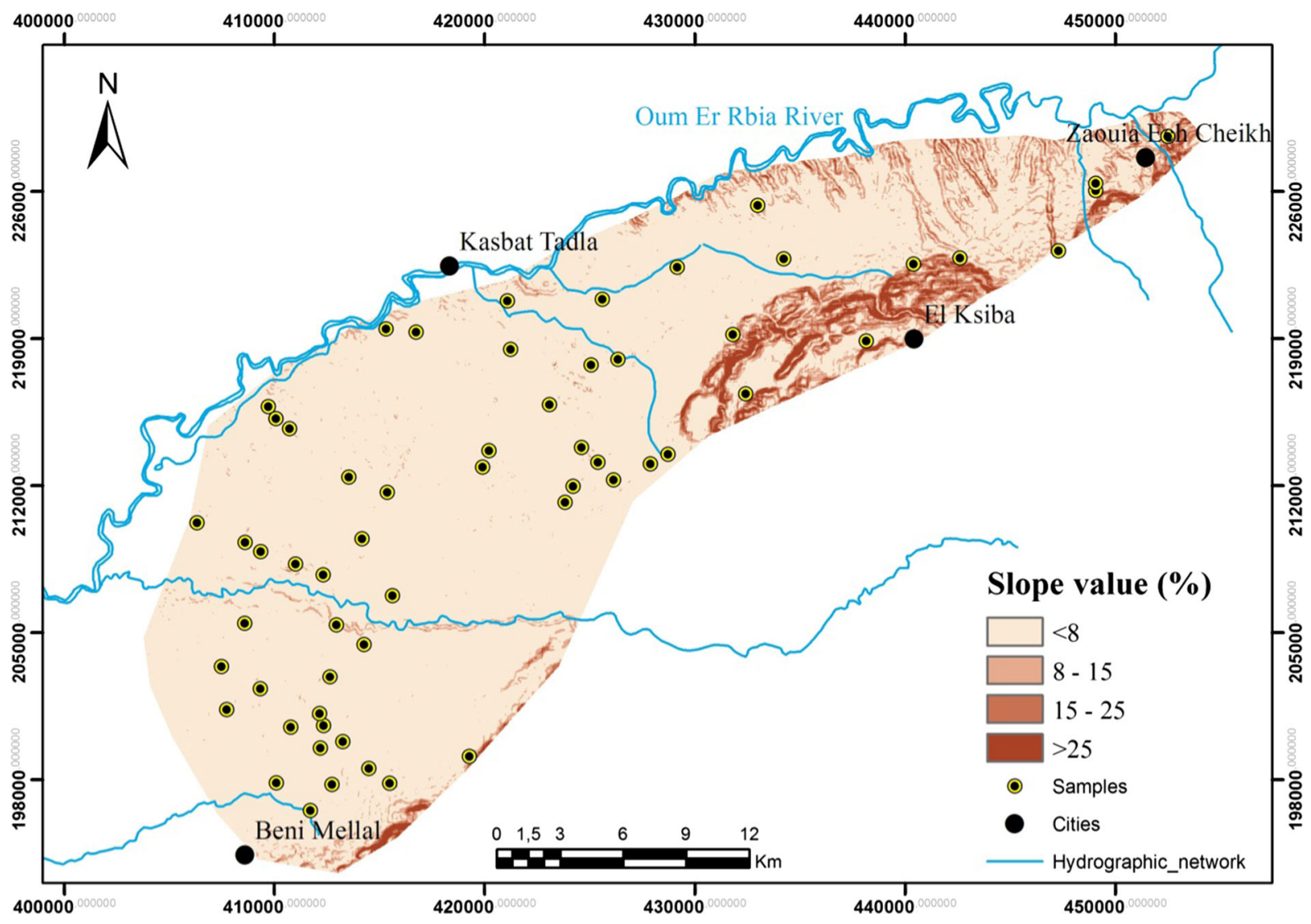

Figure 8. Spatial distribution of slope in the study area. 


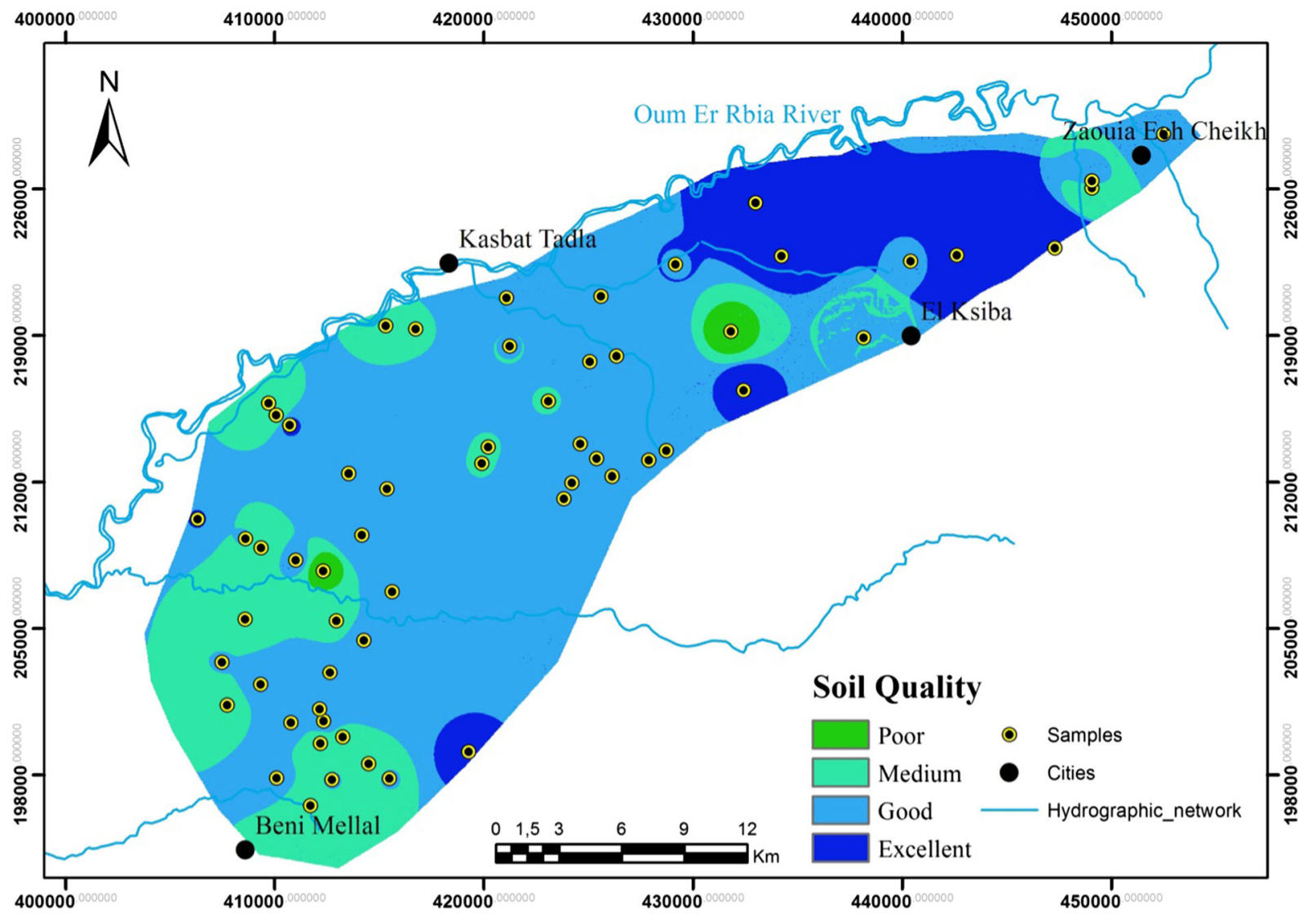

Figure 9. Map of soil suitability for intensive agriculture.

Table 5. Land suitability classes.

\begin{tabular}{lrl}
\hline \multirow{2}{*}{$\begin{array}{c}\text { Suitability } \\
\text { class }\end{array}$} & \multicolumn{2}{c}{ Area } \\
\cline { 2 - 3 } & ha & $\%$ \\
\hline Poor & 787.56 & 1.12 \\
Medium & 14714.61 & 20.97 \\
Good & 42849.74 & 61.08 \\
Excellent & 11807.51 & 16.83 \\
Total & 70159.42 & 100 \\
\hline
\end{tabular}

land degradation, excessive irrigation, and soil salinization. These effects could undoubtedly reduce the fertility and ability of the soil to sustain crop growth, which could affect consequently agricultural production.

From the results of our study and other observations made by a number of researchers for land suitability analysis (LSA) and land use planning and management (Schwilch 2011; Nyeko 2012; Barakat et al. 2017a), we infer that it is more important to invest in the prior characterization of soil quality in order to limit economic and environmental costs of soil amendments. It is true that the intensive agriculture contributes to meeting the increased global food demand, but in the medium term, it can be harmful to the environment by contributing to water and soil pollution, depletion of these resources, and destruction of biodiversity.

Water resources in the study area are decreasing more and more due to the cumulative impact of the years of drought and anthropogenic pollution (Benkaddour 2011; Barakat et al. 2016b; Knouz et al. 2016). This pollution is mainly attributed to the intensive use of fertilizers and phytosanitary products. An estimate of nitrate pollution from the use of nitrogen fertilizers shows that about 3000 tons of nitrogen are annually leached and reach the Tadla water table (ABHOER 2017). Faced with this alarming situation, and given the awareness of citizens, consumers and stakeholders in the agricultural sector, there is an urgent need to address the challenge of protecting water resources by means of conservation of soil quality and biodiversity by introducing less intensive farming systems that preserve the environment. Among the less intensive agricultural practices, it is necessary to adopt the appropriate crop types to each soil quality in order to minimize the use of inputs (fertilizers and other improvers) whose 
leaching through rain or irrigation water is one of the main causes of pollution of rivers and aquifers. Reliable and accurate soil quality evaluation is therefore indispensable to any practical soil management policies for sustainable agriculture in the study area. Several researchers throughout the world have demonstrated the usefulness of preliminary soil quality studies for agricultural purposes, because the soil elements determine its suitability for intensive agriculture (Akınc1 et al. 2013; Zolekar and Bhagat 2015; Dadhich et al. 2017; Nasrollahi et al. 2017). The quality of the soils allows targeting the crops according to their nutritional demands. It would be advisable to grow very demanding crops on better soils. On the other hand, low-quality crops must be grown regardless of soil quality.

For these kinds of preliminary studies like our own, the multi-criteria evaluation approach based on GIS decision rules constitutes an ideal tool because of its ability to derive information from different sources to map agricultural suitability properly.

\section{Conclusion}

The present study was conducted to assess the suitability of the present agricultural lands in the northeast area of Tadla plain for sustainable intensive agriculture using GIS and AHP approaches. Six soil quality indicators, namely $\mathrm{pH}, \mathrm{OC}, \mathrm{CEC}$, texture, soil salinity and slope, were used in the present investigation. AHP approach was applied to estimate the weights of indicators and subindicators to account their influences in selecting suitable land for intensive agriculture. ArcGIS spatial analyst was used to generate the thematic maps using IDW interpolation, and then, each thematic map was rasterized based on weights obtained from AHP. The calculator function of ArcGIS and overlay analyses of ArcGIS spatial analyst were used to produce the final suitability map. Based on the final suitability map of the study area, soil capability for sustainable agriculture was classified into excellent, good, medium and poor suitability classes. The results indicate that $16.83 \%$ has excellent suitability, $61.08 \%$ has good suitability, $20.97 \%$ has medium suitability, and $1.12 \%$ of the study area has poor suitability for a sustainable intensive agriculture. The AHP multi-criteria method has also demonstrated its usefulness as assessment approach of soil quality and land suitability for intensive agriculture.

\section{Acknowledgment}

We would like to express our thanks to our colleague from the University of South Dakota, Abdelali Barakat, for his editing the manuscript.

\section{References}

ABHOER (Agence du Bassin Hydraulique de l'Oum Er Rbia) 2017 Etat de la qualité des ressources en eau; http://www.abhoer.ma/index.cfm?gen=true\& $\mathrm{id}=28 \&$ ID_PAGE $=109$.

Aderonke D O and Gbadegesin G A 2013 Spatial variability in soil properties of a continuously cultivated land; Afr. J. Agric. Res. 8 475-483.

Akıncı H, Özalp A Y and Turgut B 2013 Agricultural land use suitability analysis using GIS and AHP technique; Comput. Electron. Agric. 97 71-82.

Aparicio V and Costa J L 2007 Soil quality indicators under continuous cropping systems in the Argentinean Pampas; Soil Tillage Res. 96 155-165.

Atalay I 2006 The effects of mountainous areas on biodiversity: A case study from the northern Anatolian Mountains and the Taurus Mountains; Grazer. Schr. Geogr. Raum. 41 17-26.

Barakat A, Ouargaf Z and Touhami F 2016a Identification of potential areas hosting aggregate resources using GIS method: A case study of Tadla-Azilal Region, Morocco; Environ. Earth Sci. 75 774, https://doi.org/10.1007/ s12665-016-5613-6.

Barakat A, El Baghdadi M, Rais J, Aghezzaf B and Slassi M 2016b Assessment of spatial and seasonal water quality variation of Oum Er Rbia River (Morocco) using multivariate statistical techniques; Intern. Soil Water Conserv. Res. 4 284-292.

Barakat A, Ennaji W, El Jazouli A, Amediaz R and Touhami F 2017a Multivariate analysis and GIS-based soil suitability diagnosis for sustainable intensive agriculture in Beni-Moussa irrigated subperimeter (Tadla plain, Morocco); Model. Earth Syst. Environ. 3(1) 1-8.

Barakat A, Hilali A, El Baghdadi M and Touhami F 2017b Landfill site selection with GIS-based multi-criteria evaluation technique. A case study in Béni Mellal-Khouribga Region, Morocco; Environ. Earth Sci. 76 413, https://doi. org/10.1007/s12665-017-6757-8.

Bastida F, Zsolnay A, Hernández T and García C 2008 Past, present and future of soil quality indices: A biological perspective; Geoderma 147 159-171.

Benkaddour R et al. 2011 Salinité et pollution par les nitrates des eaux souterraines de la plaine des Triffa; Rev. Marocaine Sci. - Agronom. Vétérin. 24 147-158.

Bouchaou L et al. 2009 Origin and residence time of groundwater in the Tadla basin (Morocco) using multiple isotopic and geochemical tools; J. Hydrol. 379(3) 323-338.

Bremer E and Ellert K 2004 Soil quality indicators: A review with implications for agricultural ecosystems in Alberta; AESA.

Cay T and Uyan M 2013 Evaluation of reallocation criteria in land consolidation studies using the analytic hierarchy process (AHP); Land Use Policy 30 541-548. 
Cengiz T and Akbulak C 2009 Application of analytical hierarchy process and geographic information systems in land-use suitability evaluation: A case study of Dümrek village (Çanakkale, Turkey); Int. J. Sust. Dev. World 16 286-294.

Dadhich G, Patel P R and Kalubarme M H 2017 Agriculture land suitability evaluation for wheat cultivation using geomatics for Patan District, India; IJARGE 13 91-108.

Debbarh A and Badraoui M 2001 Irrigation et environnement au Maroc: situation actuelle et perspectives; Atelier du PCSI (Programme Commun Systèmes Irrigués) sur une Maîtrise des Impacts Environnementaux de l'Irrigation; Cirad-IRD-Cemagref.

El Harti A et al. 2016 Spatiotemporal monitoring of soil salinization in irrigated Tadla plain (Morocco) using satellite spectral indices; IJAEO $\mathbf{5 0}$ 64-73.

Feizizadeh B and Blaschke T 2013 Land suitability analysis for Tabriz County, Iran: A multi-criteria evaluation approach using GIS; J. Environ. Plan. Manag. 56 $1-23$.

Filep T, Zacháry D and Balog K 2016 Assessment of soil quality of arable soils in Hungary using DRIFT spectroscopy and chemometrics; Vibrat. Spec. 84 16-23.

Herrick J E, Brown J R, Tugel A J, Shaver P L and Havstad K M 2002 Application of soil quality to monitoring and management; Agron. J. 94(1) 3-11.

Kazemi H, Sadeghi S and Akinci H 2016 Developing a land evaluation model for faba bean cultivation using geographic information system and multi-criteria analysis (A case study: Gonbad-Kavous region, Iran); Ecol. Indic. $\mathbf{6 3}$ $37-47$.

Khormi H M and Kumar L 2013 Using geographic information system and remote sensing to study common mosquito-borne diseases in Saudi Arabia: A review; $J$. Food Agric. Environ. 11(2) 14-17.

Knouz N, Boudhar A, Bachaoui E M and Aghzaf B 2016 Étude de la vulnérabilité des nappes à la pollution en zones semi-arides: cas de la nappe phréatique des Béni Amir au Maroc. Méditerranée; http://mediterranee. revues.org/7853.

Kucharik C J, Brye K R, Norman J M, Foley J A, Gower S T and Bundy L G 2001 Measurements and modeling of carbon and nitrogen cycling in agro ecosystems of southern Wisconsin: Potential for SOC sequestration during the next 50 years; Ecosystems 4 237-258.

Laskar A 2003 Integrating GIS and multicriteria decision making techniques for land resource planning; ITC Netherlands.

Metson A J 1956 Methods of chemical analysis for soil survey samples; Bull. NZ Dept. Scient. Md Res. Soil Bur. 12.

McLean E O 1982 Soil pH and lime requirement. Methods of soil analysis. Part 2; Chemical and Microbiological Properties, pp. 199-224.

Mokarram M and Hojati M 2017 Using ordered weight averaging (OWA) aggregation for multi-criteria soil fertility evaluation by GIS (Case study: southeast Iran); Comput. Electron. Agric. 132 1-13.

Nasrollahi N, Kazemi H and Kamkar B 2017 Feasibility of ley-farming system performance in a semi-arid region using spatial analysis; Ecol. Indic. $\mathbf{7 2} 239$ 248.

Nie Y, Yu J, Peng Y, Wu Y, Yu L, Jiang Y and Zhou Y 2016 A comprehensive evaluation of soil fertility of cultivated land: A GIS-based soil basic niche-fitness model; Commun. Soil Sci. Plant Anal. 47 670-678.

Nguyen T T, Verdoodt A, Van Y T, Delbecque N, Tran T C and Van Ranst E 2015 Design of a GIS and multicriteria based land evaluation procedure for sustainable land-use planning at the regional level; Agric. Ecosyst. Environ. 200 1-11.

Nyeko M 2012 GIS and multi-criteria decision analysis for land use resource planning; J. Geogr. Inf. Syst. 4 341348.

Richard L A 1954 Determination of the properties of saline and alkali soils; United States Department of Agriculture Handbook 60 7-53.

Saaty T L 1977 A scaling method for priorities in hierarchical structures; J. Math Psychol. 15(3) 234-281.

Saaty T L 1990 An exposition of the AHP in reply to the paper 'Remarks on the analytic hierarchy process'; Manag. Sci. 36 259-268.

Saaty T L and Vargas L G 2001 The seven pillars of the analytic hierarchy process; Multiple Criteria Decision Making in the New Millennium, Heidelberg, Berlin, pp. $15-37$.

Schiefer J, Lair G J and Blum W E 2015 Indicators for the definition of land quality as a basis for the sustainable intensification of agricultural production; Int. Soil Water Conserv. Res. 3 42-49.

Schwilch G et al. 2011 Experiences in monitoring and assessment of sustainable land management; Land Degrad. Dev. 22(2) 214-225.

Tanji K K 2002 Salinity in the soil environment; In: Salinity: Environment-plants-molecules, Springer, Netherlands, pp. 21-51.

Wali E, Datta A, Shrestha R P and Shrestha S 2016 Development of a land suitability model for saffron (Crocus sativus L.) cultivation in Khost Province of Afghanistan using GIS and AHP techniques; Arch. Agron. Soil Sci. 62 921-934.

Yalew S G, Griensven A, Mul M L and Zaag P 2016 Land suitability analysis for agriculture in the Abbay basin using remote sensing, GIS and AHP techniques; Model. Earth Syst. Environ. 2 1-14.

Zhang J, Su Y, Wu J and Liang H 2015 GIS based land suitability assessment for tobacco production using AHP and fuzzy set in Shandong province of China; Comput. Electron. Agric. 114 202-211.

Zolekar R B and Bhagat V S 2015 Multi-criteria land suitability analysis for agriculture in hilly zone: Remote sensing and GIS approach; Comput. Electron. Agric. 118 300-321. 